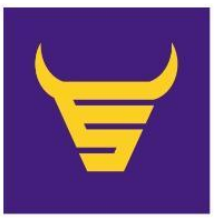

ES Materials and Manufacturing

Dol: https://dx.doi.org/10.30919/esmm5f940

\title{
Correction: Recent Advances in Thermal Interface Materials
}

Yongcun Zhou, ${ }^{1,2, *}$ Siqi Wu, ${ }^{1}$ Pengli Zhu,${ }^{3}$ Feixiang Wu ${ }^{4}$ Feng Liu, ${ }^{1,5}$ Vignesh Murugadoss, ${ }^{6,7}$ Williams Winchester, ${ }^{8}$ Amit Nautiyal, ${ }^{8}$ Zhe Wang,,${ }^{8,}$ and Zhanhu Guo ${ }^{7, *}$

Received date: 18 November 2020; Accepted date: 19 November 2020

Article type: Correction article

Some errors were found and should be corrected such as some data errors and manual errors in the 2.1 Model to Predict Thermal Conductivity ( $\left.\lambda_{\text {TIM }}\right)$ and Table 4 . Thermal conductivity of common types of fillers for the paper entitled "Recent Advances in Thermal Interface Materials" in ES Materials \& Manufacturing, 2020, 7, 4-24, (DOI: 10.30919/esmm5f717). ${ }^{[1]}$

\section{In previously published paper:}

Table 2 lists various models to predict $\lambda_{c}$. Prasher et al. ${ }^{[19,22]}$ found that Bruggeman asymmetric model (BAM) matches the experimental data of various polymeric TIM. BAM is very successful in modeling $\lambda_{\text {TIM }}$. BAM matches the data by

1 School of Material Science and Engineering, Northwestern Polytechnical University, Xi'an 710072, China

${ }^{2}$ Yangtze River Delta Research Institute of NPU, Taicang 215400, China

${ }^{3}$ Shenzhen Institute of Advanced Electronic Materials, Shenzhen Fundamental Research Institutions, Shenzhen Institutes of Advanced Technology, Chinese Academy of Sciences, Shenzhen 518055, China

${ }^{4}$ School of Metallurgy and Environment, Central South University, Changsha 410083, China

5 Analytical \& Testing Center, Northwestern Polytechnical University, Xi'an 710072, China

${ }^{6}$ Electro-Materials Research Laboratory, Centre for Nanoscience and Technology, Pondicherry University, Puducherry 605014, India

${ }^{7}$ Integrated Composites Laboratory (ICL), Department of Chemical and Biomolecular Engineering, University of Tennessee, Knoxville, TN 37996, USA

${ }^{8}$ Chemistry Department, Xavier University of Louisiana, New Orleans 70125, USA

*Email: yczhou@nwpu.edu.cn (Y. Zhou); zwang@xula.edu (Z. Wang); zguo10@utk.edu (Z.Guo), nanomaterials2000@gmail.com assuming $\alpha$ (Biot number) of 0.1 . Assuming $\lambda_{m}$ of 0.2 $\mathrm{W} / \mathrm{m} \cdot \mathrm{K}$ and particle diameter $(d)$ of $10 \mu \mathrm{m}$ (typical in commercial TIMs), $\alpha=0.1$ gives $R_{\mathrm{b}}=5 \times 10^{6} \mathrm{~K} \mathrm{~m}^{2} \mathrm{~W}^{-1} . R_{\mathrm{b}}$ at the interface between the particle and the matrix could arise due to phonon acoustic mismatch or incomplete wetting of the interface by the polymer. $R_{\mathrm{b}}$ due to phonon acoustic mismatch is of the order of $10^{-8} \mathrm{~K} \mathrm{~m}^{2} \mathrm{~W}^{-1}$ at room temperatures, resulting in $\alpha$ of 0.0002 for the case with $d$ of $10 \mu \mathrm{m}$ and $\lambda_{m}$ of $0.2 \mathrm{~W} / \mathrm{m} \cdot \mathrm{K}$. Prasher et al. also showed that phonon acoustic mismatch at room temperature is negligible when compared to incomplete particle wetting; however, phonon acoustic mismatch Table 1.

\section{The corrections:}

Table 2 lists various models to predict $\lambda_{c}$. Prasher et al. ${ }^{[19,22]}$ found that Bruggeman asymmetric model (BAM) matches the experimental data of various polymeric TIM. BAM is very successful in modeling $\lambda_{\text {TIM }}$. BAM matches the data by order of $10^{-8} \mathrm{~K} \mathrm{~m}^{2} \mathrm{~W}^{-1}$ at room temperatures, resulting in $\alpha$ of 0.0002 for the case with $d$ of $10 \mu \mathrm{m}$ and $\lambda_{m}$ of $0.2 \mathrm{~W} / \mathrm{m} \cdot \mathrm{K}$. assuming $\alpha$ (Biot number) of 0.1 . Assuming $\lambda_{m}$ of 0.2 $\mathrm{W} / \mathrm{m} \cdot \mathrm{K}$ and particle diameter $(d)$ of $10 \mu \mathrm{m}$ (typical in commercial TIMs), $\alpha=0.1$ gives $R_{\mathrm{b}}=5 \times 10^{-6} \mathrm{~K} \mathrm{~m}^{2} \mathrm{~W}^{-1} . R_{\mathrm{b}}$ at the interface between the particle and the matrix could arise due to phonon acoustic mismatch or incomplete wetting of the interface by the polymer. $R_{\mathrm{b}}$ due to phonon acoustic mismatch is of the order of $10^{-8} \mathrm{~K} \mathrm{~m}^{2} \mathrm{~W}^{-1}$ at room temperatures, resulting in $\alpha$ of 0.0002 for the case with $d$ of $10 \mu \mathrm{m}$ and $\lambda_{m}$ of $0.2 \mathrm{~W} / \mathrm{mK}$. Prasher et al. also showed that the mismatch between phonon and acoustic at room temperature is negligible when compared to incomplete particle wetting; however, this mismatch will influence the palpometers in Table 1 . 


\section{The previously published:}

Table 4. Thermal conductivity of common types of fillers

\begin{tabular}{cc}
\hline Materials & Conductivity $\left(\mathbf{W ~ m}^{-\mathbf{1}} \mathbf{K}^{-1}\right)$ \\
\hline Graphene & 600 \\
SWCNT & 3500 \\
MWCNT & 3000 \\
Diamond & 2000 \\
Graphite & $100-400$ (in-plane) \\
$\mathrm{BN}$ & $250-300$ \\
$\mathrm{Ag}$ & 427 \\
$\mathrm{Cu}$ & 393 \\
$\mathrm{Au}$ & 315 \\
$\mathrm{Al}$ & 237 \\
$\mathrm{BeO}$ & 218 \\
$\mathrm{AlN}$ & 170 \\
$\mathrm{Al} 2 \mathrm{O} 3$ & 39 \\
$\mathrm{Zno}$ & 21 \\
$\mathrm{SiO} 2$ & 1 \\
\hline
\end{tabular}

\section{The corrections:}

Table 4. Thermal conductivity of common types of fillers.

\begin{tabular}{|c|c|}
\hline Materials & Conductivity $\left(\mathrm{W} \mathrm{m}^{-1} \mathbf{K}^{-1}\right)$ \\
\hline Graphene & 6000 \\
\hline SWCNT & 3500 \\
\hline MWCNT & 3000 \\
\hline Diamond & 2000 \\
\hline Graphite & 100-400 (in-plane) \\
\hline $\mathrm{BN}$ & $250-300$ \\
\hline $\mathrm{Ag}$ & 427 \\
\hline $\mathrm{Cu}$ & 393 \\
\hline $\mathrm{Au}$ & 315 \\
\hline $\mathrm{Al}$ & 237 \\
\hline $\mathrm{BeO}$ & 218 \\
\hline AlN & 170 \\
\hline $\mathrm{A} 12 \mathrm{O} 3$ & 39 \\
\hline $\mathrm{ZnO}$ & 21 \\
\hline $\mathrm{SiO} 2$ & $1.4^{[2]}$ \\
\hline
\end{tabular}

\section{References:}

[1] Y. C. Zhou, S. Q. Wu, P. L. Zhu, F. X. Wu, F. Liu, V. Murugadoss, W. Winchester, A. Nautiyal, Z. Wang and Z. H. Guo, ES Mater. Manuf., 2020, 7, 4-24, doi: 10.30919/esmm5f717

[2] W. H. Zhu, G. Zheng, S. Cao and H. He, Sci. Rep., 2018, 8, 10537, doi: 10.1038/s41598-018-28925-6.

Publisher's Note Engineered Science Publisher remains neutral with regard to jurisdictional claims in published maps and institutional affiliations. 